\title{
A Novel Load Shedding Strategy Combining Undervoltage and Underfrequency with Considering of High Penetration of Wind Energy
}

\author{
*Hao-Tian Zhang, MIEEE; +Chun Sing Lai, Student MIEEE; *Loi Lei Lai, FIEEE; *Fangyuan Xu, MIEEE \\ *State Grid Energy Research Institute, Beijing China; abhb779@163.com \\ +Engineering Science, University of Oxford, UK; Chun.lai@eng.ox.ac.uk
}

\begin{abstract}
Low carbon emission is one of the main targets for smart grid planning. To achieve this goal, intermittent energies such as wind and solar are integrated to the power systems increasingly. However, this may create huge challenges to the power system operators for balancing the generation and demand at all times and guaranteeing the system reliability at the same time. With high penetration of renewable energies, power system operators are compelled to curtail the loads when the power system cannot rely on power from renewable energies continuously due to strong dependence on the environment. As an important defense to protect the power network from collapsing and to keep the system integrating, load shedding has been designed and proposed for decades. However, most of the shedding schemes consider the load increasing instead of lack of generation. This paper applies a load shedding scheme with considering both voltage and frequency changes when the generation is inadequate since the power system cannot obtain the expected renewable generation and renewable energies are highly penetrated into the grid.
\end{abstract}

Index Terms-Load shedding, undervoltage, underfrequency

\section{INTRODUCTION}

One of the main goals for smart grid is to lower carbon emission and prevents the environment from pollution. Basically, there are two main solutions for lowering carbon emission, increasing sustainable energy source investment at the generation side and demand side management. From the generation side consideration, both developing countries and developed countries around the world have a clear goal on renewable energy development and planning. According to the China's plan, renewable energy consumption will occupy $15 \%$ of the total energy consumption by 2020 [1]. Scotland is committed to generate an equivalent of $100 \%$ electricity demand from renewable sources by 2020 , which is the most ambitious in the European Union [2]. Ireland has already met the target of $19.6 \%$ of the electricity demand by renewable sources in 2012, and set the target of $40 \%$ of demand by renewable sources by 2020 [3]. The U.S. government devotes to achieve $20 \%$ wind energy by 2030 [4]. The renewable production (especially wind) of China ranks No.1 of the world in 2014. However, the wind production in China only occupies approximately $7 \%$ of the total energy structure as the electricity produced by fossil fuels was increased at the same time.

However, with the increasing number of sustainable energy sources integrated to power grid, decreasing of carbon emission may accompany with power stability challenges. For instance, due to high dependence on the environment such as wind speed, wind direction, solar radiation and temperature, wind and solar energy sources are intermittent and fluctuating at all time. Although countries around the world have developed Grid Codes [5-7] to stipulate the requirement of active and reactive power controls in a wind farm or solar farm, challenges are still existing on balancing the total generation and demand in a power grid. For instance, weather changes suddenly can strongly affect the output power from the wind and solar generation within a short time. With small number of storage devices installed in the grid and if no redundant spinning reserve in the situation, generation could not support the load any longer in the power network. Load curtailment plan may need to be triggered to keep the power network as integrated as possible. To the authors' best knowledge, there is no literature to consider the load shedding case when lack of generation, especially with large intermittent renewable energy integrated into the grid.

As the final solution to deal with the large area blackout, load shedding plays a very important role to survive the network and keep the whole network as integrated as possible. Underfrequency Load Shedding (UFLS) schemes have been proposed for decades to prevent the frequency from declining, which may result in destructive damage of the generators' components. For example, nuclear power plants usually act as base loads are strictly operated with a frequency above $48 \mathrm{~Hz}$, whereas some hydro units may work with a frequency as low as $45 \mathrm{~Hz}$ for frequency balancing purposes [8]. In order to prevent the frequency from declining, reducing electrical loads with less importance is normally desired by manual or automatic load shedding schemes which are proposed in [9- 
14]. However, load curtailment only with tripping underfrequency relays is not enough to survive the network especially in heavy load conditions or when system is suffering from loss-of-mains event. UFLS schemes only consider the impact from the system frequency and the real power balancing between generation and demand, while the system impact from voltage drop and reactive power balancing is neglected.

Some of the major power system disturbances are caused by voltage collapse rather than underfrequency conditions. Load shedding relying on underfrequency UFLS relays may not be sufficient. Power systems today are much more vulnerable to voltage collapse than before as the power plants are usually established far away from the load area, and the power has to be delivered to customers via long distance transmission system which results in increasing in reactive power loss. Consequently, voltage based load shedding schemes have to be applied into the grid for maintaining the voltage level. Besides, one of the extraordinary advantages with applying undervoltage load shedding relay is that the voltage respond speed is much faster than that of frequency, which may provide more accurate system status to system operators, because the voltage response is electrical phenomena, whereas the frequency response is a mechanical one. However, this does not mean underfrequency relay is neglected if the undervoltage load shedding relays have been deployed. Undervoltage relays protect the local bus voltages from decaying, while shedding the loads by operating undervoltage relays. If system frequency still cannot be maintained more loads need to be curtailed by further operating underfrequency relays.

Many undervoltage load shedding schemes have been proposed [15-21]. From the literatures, it can be summarized into two main undervoltage load schemes, that is, distributed undervoltage load shedding and centralized load shedding schemes. The distributed undervoltage scheme applies to a number of distributed controllers coupled to the key nodes of the power network which covers a set of loads and measures the voltage signal locally. Centralized load shedding schemes relies on communication technologies to transmit the voltage and any other signals which measured locally to a control centre for further load shedding decision making. For instance, an adaptive wide-area closed-loop undervoltage load shedding by synchronized measurements was proposed in [17].

Although there are plenty of load shedding schemes proposed to prevent the power system from splitting up, load shedding schemes, nevertheless, are rarely proposed for considering cases under generation inadequate, especially when renewable energies are highly dominated in the energy mix. With the wind penetration level increasing in China, load shedding for considering highly wind penetration is extremely urgent. This paper proposes a load shedding scheme for those power systems with large amount of intermittent renewables integrated, considering both frequency and voltage impacts. In practice, unit protection device inside the wind generators will trip when the system suffering from voltage or frequency instability. In order to demonstrate the result clearly, this paper only concentrates on the load shedding relay deployment, whereas the relays to protect the wind turbines are not considered in the case study. The proposed load shedding scheme is studied in a modified IEEE New England 39-bus system. This paper is organized as follows: Section II gives the detailed explanation of the proposed shedding scheme, three important stages for planning the scheme, determination of the location, amount of load shedding and voltage setting are discussed. Two scenarios, wind penetration level 5\% and $30 \%$, for load shedding strategy are studied in Section III, a modified IEEE 39-bus system is modelled to examine the proposed load shedding scheme. Conclusions and future work are given in Section IV.

\section{Proposed LOAD SHEDDING SCHEME}

Load shedding is to prevent the network from collapsing by means of examining the system signals. Underfrequency load shedding scheme usually examines the system frequency and rate of change of frequency, while undervoltage load shedding examines the local voltage at some key nodes. It may need to curtail the load to some degrees to maintain the network integration when the network is suffering from large disturbance. It may not be sufficient to determine the load curtailment only by underfrequency load shedding scheme, or only by undervoltage load shedding scheme, because the undervoltage load shedding is to curtail the load locally at the busbar hits the voltage limit. The underfrequency relays protect the frequency of the entire network from further decaying.

Unlike sudden generator lost or sudden load increase, it is a dynamic situation to reduce wind energy when the wind speed is getting lower. In this case study, a model based on cosine wave for illustrating the wind speed change is applied to simulate the system behavior. For investigating the generation decrease due to wind speed reduction, only the decreasing part of the model is taken into consideration. The wind speed model is illustrated with Equation (1).

$$
v_{\text {wind }}=\frac{G_{\max }}{2} \cdot\left[1-\cos \left(2 \pi \cdot \frac{t-\frac{T}{2}}{T}\right)\right] \quad 0<t<T
$$

Where $G_{\max }$ is the maximum value of the wind speed, $T$ is the gust period, and $t$ is time.

To design a load shedding scheme, it is necessary to determine the number of load and time delay without decreasing the system security level. Generally, there are three main steps to design a load shedding scheme. First of all, determine the stages for load shedding. In this step, when the load shedding begins, time delays in each stage are determined. Time delay and settings have to be considered and coordinate with local protection devices. Secondly, select the load curtailment locations. Lastly, determine the number of loads to be reduced in each step. It is worth noting that the load characteristics might affect voltage stability and undervoltage load shedding. The amount of load to be reduced has to be determined locally. Both insufficient load shedding and redundant load shedding will cause the generators, or even the whole system unstable. In this case study, voltage dependent loads are considered for the load shedding scheme. The description is shown in Equations (2) and (3). To simplify 


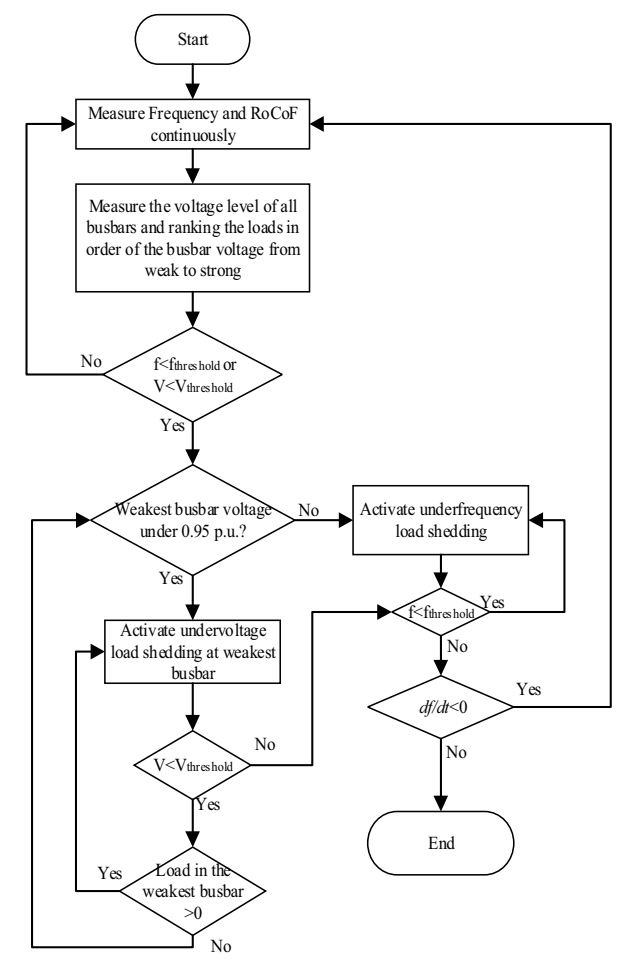

Figure 1. Proposed load shedding scheme

the model, only one component with one exponent is counted for in this case.

$$
P=P_{0}\left(\frac{v}{v_{0}}\right)^{e p}
$$

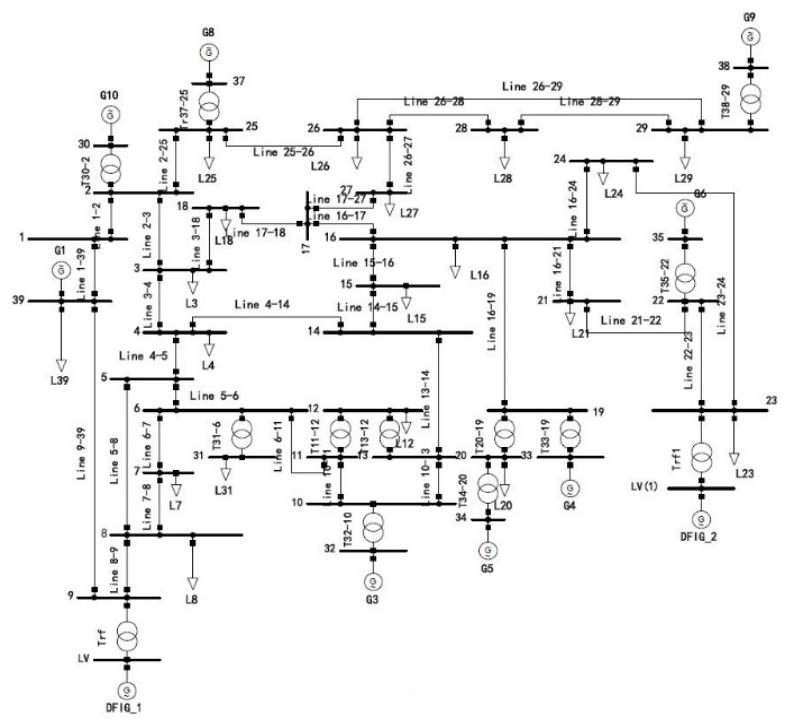

Figure 2. Modified IEEE 39-bus system

$$
Q=Q_{0}\left(\frac{v}{v_{0}}\right)^{e q}
$$

Where $\mathrm{P}_{0}$ and $\mathrm{Q}_{0}$ are the initial loads value, $v$ is the bus voltage magnitude, $v_{0}$ is the initial value of the voltage at the bus, and $e p$ and $e q$ are the voltage dependence exponent value. $e \mathrm{p}$ and $e \mathrm{q}$ are set to 0.5 .

\section{A. Determination of undervoltage load shedding location}

One of the important steps for design load shedding scheme is to select load shedding locations. Selecting load shedding location arbitrarily may result in more loads to be taken away. Although the region prone to voltage instability is known beforehand in practice, the weakest busbar may vary in terms of the disturbance place and system topology. In this case study, Load 8 at the Bus 8 is set with a load to take the voltage to 0.95 p.u. With the power output from the wind turbine decreasing, the voltage in Bus 7 and Bus8 is decaying. It can be seen that Bus 8 is much weaker than Bus 7. In another word, the voltage decays faster at Bus 8 than that in Bus 7.

\section{B. Time setting for undervoltage relay}

Time setting for undervoltage load shedding is a very critical step. Time setting of the relay must be short enough to prevent the voltage from collapsing. At the same time, the time setting must be long enough to avoid mal-operation when small disturbance occurring in the system. Time setting can be determined by Equation (4).

$$
C=\int_{0}^{T} \Delta V(t) d t
$$

Where $C$ is a constant, $\Delta V(t)$ is the difference between the voltage and voltage threshold. $T$ is the time setting of the undervoltage relay.

\section{Determination of load shedding amount}

Shedding load only with underfrequency relays is much simpler. The magnitude of load required to be shed is basically linked to the degree of the grid contingencies and disturbances. The resulting consequences by grid contingencies and disturbances can be measured by the dynamic imbalance between generators and demand. For undervoltage load shedding, the load shedding amount relies on the voltage drop, which can be illustrated in Equation (5).

$$
\Delta P_{\mathrm{V}}=K \cdot \int_{0}^{T} \Delta V(t) d t=K \cdot C
$$

Where $K$ is a constant. In order to prevent the unacceptable transient, each step of load shedding amount should not be set too large. Imbalance between generators and loads can be calculated with Equation (6), and total loads triggered by underfrequency relays can be computed from Equation (7).

$$
\begin{gathered}
\Delta P=\frac{2}{f_{n}} \sum_{i=1}^{N} H_{i} \frac{d f_{c}}{d t} \\
\Delta P_{f}=\Delta P-\Delta P_{\mathrm{v}}
\end{gathered}
$$




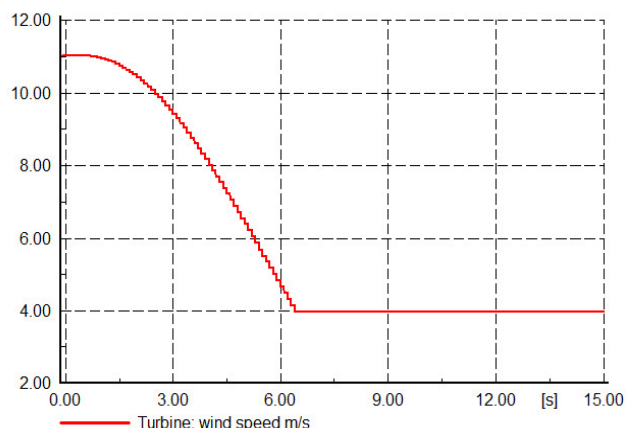

Figure 3. Wind speed for wind turbine input

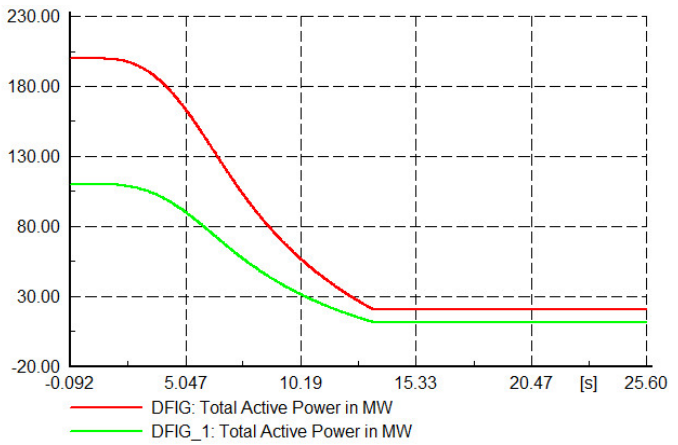

Figure 4. Output power changing of the two wind turbines with penetration level at $5 \%$

Where $H$ is the equivalent inertia, $f_{\mathrm{c}}$ is the frequency.

Figure 1 illustrates the underfrequency load shedding scheme applied to a modified IEEE New England 39-bus system. There is no doubt that the change of frequency and that of voltage are not in the same manner during load shedding. In the load shedding schemes combined with undervoltage relays, bad determination of load shedding amount can cause overfrequency, because more loads are curtailed and real power generated is greater than the system loads. Besides, some important loads like hospital, telecom service centre, traffic administration centre etc. must be guaranteed to serve with high reliability.

\section{CASE STUDY}

Figure 2 demonstrates the test system, a modified IEEE 39-busbar network with 2 wind farms instead of conventional generators connecting at Bus 9 and Bus 25 to implement the proposed methodology. Generators G2 and G7 in the original topology have been taken away and the total capacity of the system generation has been reduced. The system consists of 19 loads with active power varying from 7.5 MW to 991.8 MW, and the load data of the modified IEEE test system can be found in the appendix at the end of the paper. All circuit breakers linked from branch end to end are closed. Two load

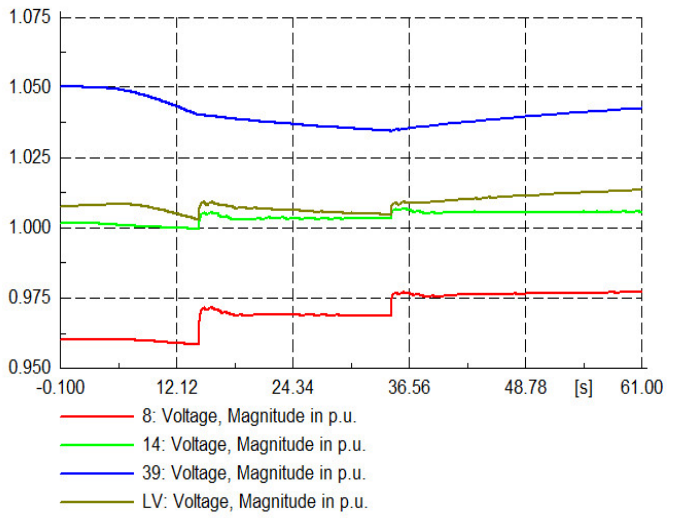

Figure 5. Voltage respond in Bus 14, LV, 39, and 8 with penetration level $5 \%$

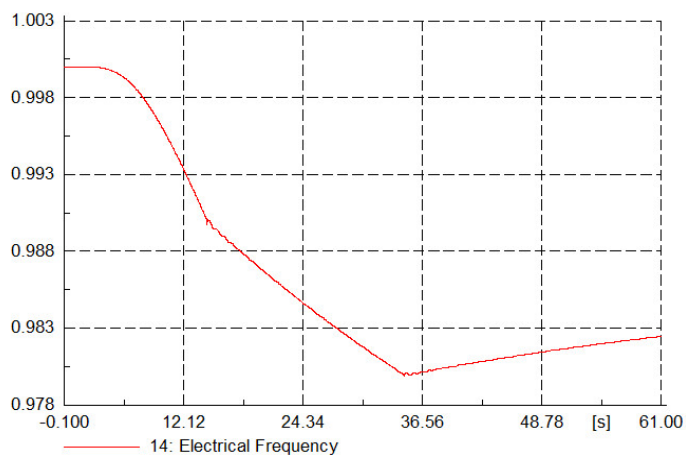

Figure 6 . System frequency at bus 14 with penetration level at 5\%

shedding cases are studied with different wind energy penetration levels $(5 \%$ and $30 \%)$ in this paper. Double-Fed Induction Generator template, which can be found in the DIgSILENT Software General Library, are applied for wind generation dynamic study. Both wind generators are suffering wind speed decaying from $11 \mathrm{~m} / \mathrm{s}$ to $4 \mathrm{~m} / \mathrm{s}$ within 6 seconds, which is shown in Figure 3. According to the scheme proposed in this paper, loads are ranked in order from the weakest to the strongest in terms of the network topology and its operation. In this paper, only undervoltage and underfrequency load shedding scheme is focused, impacts after load shedding, for instance, some bus voltages are getting very high, is neglected in the case study.

\section{A. $5 \%$ penetration level of the wind energy scenario}

In this scenario, $5 \%$ penetration means that the wind power is $5 \%$ of the total generation power. Wind generation $\mathrm{s}$ are at Bus 9 (200MW) and Bus 23 (100MW) With the wind speed decreasing rapidly, the power output of the two wind generators is decreased to $10 \%$ of the rated power, which is shown in Figure 4. 


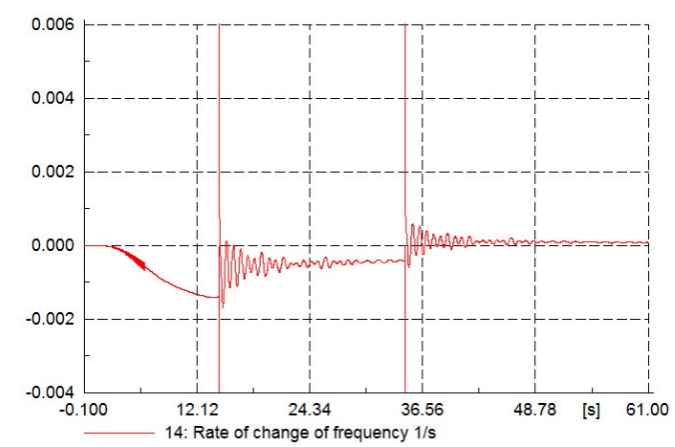

Figure 7. Rate of change of frequency at Bus 14 with penetration level

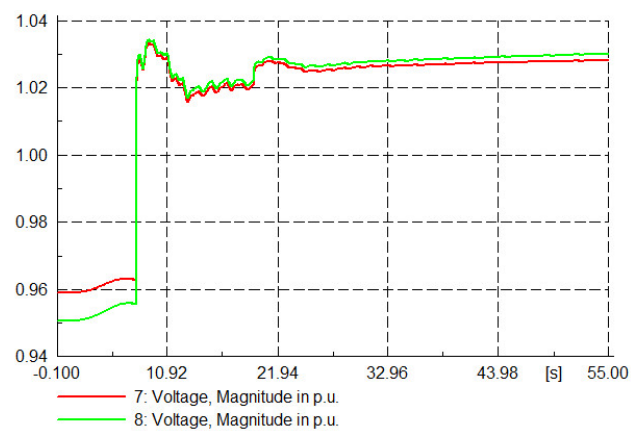

Figure 8. Voltage response in Bus 7 and Bus 8 with penetration level at $30 \%$

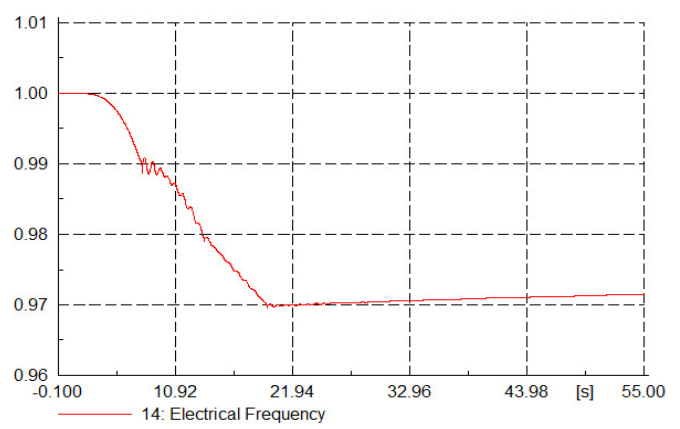

Figure 9. System frequency at Bus 14 with penetration level at $30 \%$

Voltage signals of 4 buses, 8, 14, 39 and LV bus of the wind generator are shown in Figure 5. System frequency at Bus 14 is shown in Figure 6. Apparently, the local voltage is under reasonable range and consequently the undervoltage relay will not trip. However, the system frequency is dropping and the underfrequency relay is tripping to shed $15 \%$ the load at Bus 8 when the frequency drops to $49.5 \mathrm{~Hz}$ and $10 \%$ of the load when frequency drops to $49 \mathrm{~Hz}$. The circuit breaker may operate 5-10 cycles after the frequency value measured. It can be seen that the system frequency recovers after the second step load shedding. The rate of change of frequency is shown in Figure 7.

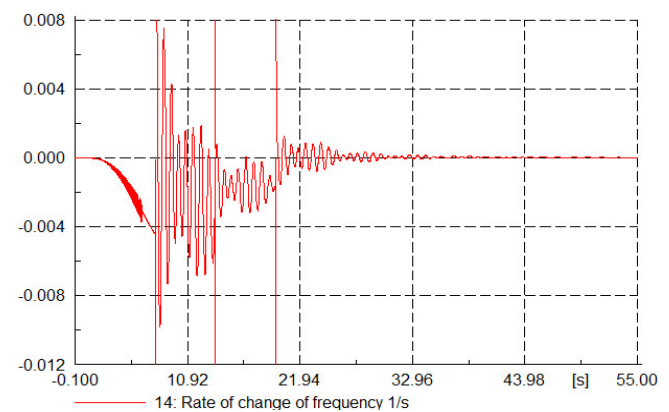

Figure 10. Rate of change of frequency at Bus 14 with penetration level at $30 \%$

\section{B. $30 \%$ penetration level of the wind energy scenario}

$30 \%$ penetration of the wind energy is connected to the system at Bus 9 and Bus 23. Each capacity of the wind farm is $900 \mathrm{MW}$. It is worth noting that the voltage level at Bus 9 is at the critical point. When the generation of wind power decreases, voltage at Bus 8 cannot support any longer and drops below 0.95 p.u. The voltage signal drops to the threshold, which is 0.95 p.u., is slower than the frequency signal reaching to the first threshold which is 0.99 p.u. Consequently, the underfrequency load shedding trips first to protect the system frequency decay. The response of voltage, frequency and rate of change of frequency are shown in Figures 8-10. After tripping the load by underfrequency load shedding relay, the voltage at the local bus is recovering. However, the system frequency is still decaying since no more power could be extracted from the wind turbine. Although the trend of the system voltage and frequency is recovering by applying the proposed load shedding scheme, it shows that there are some ripples existing after wind speed variation by applying the template wind generator model. It can be vividly depicted in Figure 8 that the voltage goes high before the relay is tripping. The reason is that the voltage dependent loads are getting smaller with the local bus voltage decay. Consequently, the voltage recovers and even gets larger than the initial value. Assuming there is no relay tripping, the voltage will decrease again since the generation is getting smaller.

\section{CONCLUSIONS AND FUTURE WORKS}

This paper proposed a novel load shedding scheme by applying undervoltage relay and gives a scientific explanation that load shedding only by examining frequency is not sufficient to protect the system from collapsing. This strategy is based on observing both voltage and system frequency. It is worth noting that undervoltage condition may be combined with overfrequency condition. Consequently, further action may be needed for generator operations. Adjustment of the electricity dispatch and overfrequency may be needed to protect the system frequency from going higher. This paper demonstrated a load shedding strategy combining voltage and frequency consideration for power systems with large intermittent renewable resources such as wind penetration.

A modified IEEE 39-bus system was built in PowerFactory DIgSILENT, a commercial power system simulation tool. DFIG wind turbine template in the software is adapted to the network for checking the proposed framework. 
As can be seen in the figures, the system frequency is recovering. Although the trend of the system voltage and frequency are recovering, it shows that there are some ripples existing after wind speed variation by applying the template wind generator model. Because lack of information on the template model, it is difficult to give the scientific reason about the ripples, which can be considered in future work. Nevertheless, it can still be concluded that the proposed scheme is an effective automatic load shedding strategy to reduce the total load shedding amount during small or large disturbances. It is foreseen that this method has practical values.

\section{ACKNOWLEDGMENTS}

Financial support from State Grid Corporation of China is very much appreciated.

\section{REFERENCES}

[1] http://www.ndrc.gov.cn/zcfb/zcfbtz/200709/W02007090460734604411 0.pdf, visited on March 29, 2015.

[2] 2020 Routemap for Renewable Energy in Scotland, http://www.gov.scot/Publications/2011/08/04110353/3, visited on March 29, 2015

[3] Offshore Renewable Energy Development Plan, http://www.dcenr.gov.ie/nr/rdonlyres/836dd5d9-7152-4d76-9da081090633f0e0/0/20140204dcenroffshorerenewableenergydevelopment plan.pdf, visited on March 29, 2015.

[4] Wind Vision: A New Era for Wind Power in the United States, http://www.energy.gov/windvision, visited on March 29, 2015.

[5] Indian Electricity Grid Code, http://www.cercind.gov.in/2010/ORDER/February2010/IEGC Review Proposal.pdf, visited on March 29, 2015.

[6] Grid Code, National Grid, http://www2.nationalgrid.com/UK/Industryinformation/Electricity-codes/Grid-Code/, visited on March 29, 2015.

[7] Technical rule for connecting wind farm to power system, Std. No. GB/T 19963-2011, Standardization Administration of P.R. China.

[8] Anderson. G, "Dynamics and control of electric power systems", Power Systems Laboratory, ETH Zurich, Feb 2011.

[9] Urban Rudez and Rafael Mihalic, "Monitoring the First Frequency Derivative to Improve Adaptive Underfrequency Load-Shedding Schemes", IEEE Transactions on Power Systems, Vol. 26, No. 2, 2011.

[10] Abbas Ketabi and Masoud Hajiakbari Fini, "An Underfrequency Load Shedding Scheme for Hybrid and Multiarea Power Systems", IEEE Transactions on Smart Grid. Vol. 6, No.1, 2015.

[11] Sarra Abdelwahid et al. "Hardware Implementation of an Automatic Adaptive Centralized Underfrequency Load Shedding Scheme", IEEE Transactions on Power Delivery, Vol. 29, No. 6, 2014.

[12] Ying-Yi Hong and Shih-Fan Wei, "Multiobjective Underfrequency Load Shedding in an Autonomous System Using Hierarchical Genetic Algorithms", IEEE Transactions on Power Delivery, Vol. 25, No. 3, 2010.

[13] Urban Rudez, and Rafael Mihalic, "Analysis of Underfrequency Load Shedding Using a Frequency Gradient", IEEE Transactions on Power Delivery, Vol. 26, No. 2, 2011.

[14] Scott Manson et al. "Case Study: An Adaptive Underfrequency LoadShedding System", IEEE Transactions on Industry Applications, Vol. 50, No.3, 2014

[15] C. Mozina, "Undervoltage load shedding", Power systems Conference: Advanced Metering, Protection, Control, Communication, and Distributed Resources, pp.39-54, 2007.

[16] Bogdan Otomega et al. "A purely distributed implementation of undervoltage load shedding", IEEE PES General Meeting, 2007, pp.17.

[17] Mevludin Glavic and Thierry Van Cutsem, "Adaptive wide-area closed-loop undervoltage load shedding using synchronized measurements", IEEE General Meeting, pp. 1-8, 2010
[18] C. S. Chen et al. "Design of Undervoltage Relay Setting for an Industrial Plant With Cogeneration Units to Enhance Power Quality of Critical Loads", IEEE Transactions on Industry Applications, Vol. 44, No. 4, 2008.

[19] Bogdan Otomega Mevludin Glavic and Thierry Van Cutsem, "Distributed Undervoltage Load Shedding", IEEE Transactions on Power Systems, vol. 22, No.4. pp. 2283-2284, Nov. 2007.

[20] S. Mark Halpin, Keith A. Harley, Robert A. Jones and Lee Y. Taylor "Slope-Permissive Under-Voltage Load Shed Relay for Delayed Voltage Recovery Mitigation", IEEE Transactions on Power Systems, pp.1211-1216, 2008.

[21] Bogdan Otomega and Thierry Van Cutsem, "Undervoltage Load Shedding Using Distributed Controllers", IEEE Transactions on Power Systems, vol. 22, No.4. pp. 1898-1907, Nov. 2007.

\begin{tabular}{|c|c|c|c|c|}
\hline \multicolumn{5}{|c|}{$\begin{array}{l}\text { TABLE I } \\
\text { LOAD DATA }\end{array}$} \\
\hline Bus No. & Load Ac & ve Power (MW) & $\begin{array}{r}\text { Load } \mathrm{r} \\
\end{array}$ & $\begin{array}{l}\text { eactive Power } \\
\text { MVAr) }\end{array}$ \\
\hline 3 & & 322 & & 2.4 \\
\hline 4 & & 500 & & 184 \\
\hline 7 & & 233.8 & & 84 \\
\hline 8 & & 939.6 & & 316.8 \\
\hline 12 & & 7.5 & & 88 \\
\hline 15 & & 320 & & 153 \\
\hline 16 & & 329 & & 32.3 \\
\hline 18 & & 158 & & 30 \\
\hline 20 & & 628 & & 103 \\
\hline 21 & & 274 & & 115 \\
\hline 23 & & 247.5 & & 84.6 \\
\hline 24 & & 308.6 & & -92 \\
\hline 25 & & 224 & & 47.2 \\
\hline 26 & & 139 & & 17 \\
\hline 27 & & 281 & & 75.5 \\
\hline 28 & & 206 & & 27.6 \\
\hline 29 & & 283.5 & & 26.9 \\
\hline \multicolumn{5}{|c|}{$\begin{array}{c}\text { TABLE II } \\
\text { GENERATOR DATA } \\
\end{array}$} \\
\hline $\begin{array}{l}\text { Unit } \\
\text { No. }\end{array}$ & $\mathbf{H}(\mathbf{s})$ & x'd (p.u.) & x'q (p.u.) & $\begin{array}{l}\text { Xd } \\
\text { (p.u.) }\end{array}$ \\
\hline 1 & 10. & 0.006 & 0.008 & 1. \\
\hline 3 & 9.308 & 0.0531 & 0.0876 & 1.1227 \\
\hline 4 & 7.436 & 0.0436 & 0.166 & 1.048 \\
\hline 5 & 6.76 & 0.132 & 0.166 & 1.206 \\
\hline 6 & 9.048 & 0.05 & 0.0814 & 1.016 \\
\hline 8 & 6.318 & 0.057 & 0.0911 & 1.16 \\
\hline 9 & 8.97 & 0.057 & 0.0587 & 1.053 \\
\hline 10 & 9. & 0.031 & 0.008 & 1. \\
\hline $\begin{array}{l}\text { Unit } \\
\text { No. }\end{array}$ & $\begin{array}{l}\text { Xq } \\
\text { (p.u.) }\end{array}$ & T'd (s) & T'q (s) & $\begin{array}{l}\text { XI } \\
\text { (p.u.) }\end{array}$ \\
\hline 1 & 0.95 & 0.84 & 0.756 & 0.003 \\
\hline 3 & 1.0665 & 0.6739478 & 0.606553 & 0.0304 \\
\hline 4 & 1.032 & 0.5918035 & 0.5326232 & 0.0295 \\
\hline 5 & 1.116 & 1.477612 & 1.329851 & 0.054 \\
\hline 6 & 0.964 & 0.89813 & 0.808317 & 0.0224 \\
\hline 8 & 1.12 & 0.8230603 & 0.7407542 & 0.028 \\
\hline 9 & 1.025 & 0.6482192 & 0.5833973 & 00298 \\
\hline 10 & 0.69 & 1.428 & 1.2852 & 0.004 \\
\hline
\end{tabular}

